\title{
Metabolic syndrome as a risk factor for high intraocular pressure: the Korea National Health and Nutrition Examination Survey 2008-2010
}

This article was published in the following Dove Medical Press journal:

Diabetes, Metabolic Syndrome and Obesity:Targets and Therapy

\author{
Yu Hyeon $\mathrm{Yi}^{1,2}$ \\ Young Hye $\mathrm{Cho}^{3}$ \\ Yun Jin Kim ${ }^{1,2}$ \\ Sang Yeoup Lee ${ }^{3}$ \\ Jeong Gyu Lee ${ }^{1,2}$ \\ Eun Hee Kong ${ }^{4}$ \\ Byung Mann Cho ${ }^{5}$ \\ Young Jin Tak ${ }^{1,2}$ \\ Hye Rim Hwang ${ }^{1,2}$ \\ Seung Hun Lee ${ }^{1,2}$ \\ Eun Ju Park ${ }^{3}$ \\ 'Department of Family Medicine, \\ Pusan National University School of \\ Medicine, Yangsan 626-780, Korea; \\ ${ }^{2}$ Department of Family Medicine, \\ Biomedical Research Institute, Pusan \\ National University Hospital, Busan \\ 626-770, Korea; ${ }^{3}$ Department of \\ Family Medicine, Research Institute of \\ Convergence of Biomedical Science \\ and Technology, Pusan National \\ University Yangsan Hospital, Yangsan \\ 626-780, Korea; ${ }^{4}$ Department of \\ Family Medicine, College of Medicine, \\ Kosin University, Busan, Korea; \\ ${ }^{5}$ Department of Preventive Medicine, \\ Pusan National University School of \\ Medicine, Yangsan 626-780, Korea
}

Correspondence: Young Hye Cho Department of Family Medicine, Obesity, Metabolism and Nutrition Center and Research Institute of Convergence of Biomedical Science and Technology, Pusan National University Yangsan Hospital, 20 Geumo-ro, Yangsan 626-

770 , Korea

$\mathrm{Tel}+82553602018$

Fax +82 553602019

Email younghey82@naver.com
Background: High intraocular pressure (IOP) is well established as the most significant risk factor for both the development and progression of primary open-angle glaucoma. Elevated IOP is more frequently seen in the presence of metabolic disturbances that are associated with the components of metabolic syndrome (MetS). The aim of this study was to investigate the association between ocular hypertension and MetS.

Patients and methods: We examined the relationship between ocular hypertension and MetS in 17,160 Korean adults without glaucoma aged $>19$ years (7,368 men and 9,792 women) who participated in the 2008-2010 Korea National Health and Nutrition Examination Survey. Multivariate logistic regression analysis was used to assess the relationship between MetS and ocular hypertension, after adjusting for age, body mass index, smoking, alcohol consumption, and regular exercise. Results: The prevalence of MetS was 35.1\% among males and 30.1\% among females. The prevalence of ocular hypertension was $1.3 \%$ among males with MetS and $0.7 \%$ among females with MetS. Participants with MetS had a significantly higher IOP than those without MetS $(P \leq 0.001)$, and each component of MetS had a different effect on the IOP. Hypertension was the strongest predictor of an elevated IOP. In multivariate regression analysis, ocular hypertension was significantly associated with MetS ( $P=0.027$ for men; $P=0.015$ for women).

Conclusion: There is a statistically significant relationship between MetS and ocular hypertension.

Keywords: intraocular pressure, glaucoma, metabolic syndrome, obesity, hypertension

\section{Introduction}

Glaucoma is a progressive optic nerve disease characterized by optic disc cupping and is a significant cause of irreversible blindness worldwide. ${ }^{1}$ The early detection and treatment of glaucoma is the key because blindness is irreversible. High intraocular pressure (IOP) is the most significant risk factor for both the development and progression of primary open-angle glaucoma. ${ }^{2}$

Metabolic syndrome (MetS) is a cluster of metabolic abnormalities that includes central obesity, hypertension, hyperglycemia, hypertriglyceridemia, and low levels of high-density lipoprotein (HDL) cholesterol. ${ }^{3}$ Diabetes mellitus (DM), hypertension, central obesity, body mass index (BMI), age, and metabolic disturbances associated with the components of MetS have been associated with elevated IOPs. ${ }^{4-7}$ It is important to identify modifiable glaucoma risk factors to prevent blindness and to optimize the factor-focused management of systemic diseases with glaucoma, such as that has been done in the treatment of cardiovascular diseases. ${ }^{8}$ Mitigation of these additional risk factors may help in the prevention and treatment of glaucoma. 
The aim of this study was to investigate the association between MetS and ocular hypertension, taking into consideration the confounding factors, including systemic health parameters. Specifically, we investigated the five key components of MetS in relation to IOP elevation.

\section{Patients and methods Data source and participants}

This study was based on data obtained from the 2008 to 2010 Korean National Health and Nutrition Examination Survey (KNHANES), a cross-sectional and nationally representative survey conducted by the Korea Center for Disease Control and Prevention and approved by its institutional review board. The KNHANES used a multistage stratified probability-clustered sampling method and a weighting scheme that allowed for the estimation of health statistics representative of noninstitutionalized civilians who resided in Korea. Additional details regarding the survey design and methods have been provided elsewhere. ${ }^{9}$ All participants in the KNHANES provided written informed consent prior to commencement of the study.

Our study subjects were Koreans who participated in the 2008-2010 KNHANES. We selected 21,811 subjects who were $\geq 19$ years of age. Among these, we excluded 2,750 subjects who had not undergone thorough ophthalmic examinations, 1,107 subjects with missing data for MetS components, 53 subjects with glaucoma, 326 subjects with a history of ophthalmic surgery, and 413 subjects who had other missing data. Thus, a total of 17,160 subjects (7,368 men and 9,792 women) were included in the analysis. The study protocol was approved by the institutional review board of the Pusan National University Hospital, Pusan, Korea (2015-11-026).

\section{Data collection}

The KNHANES consisted of a health interview and a health examination including an ophthalmological interview and examination. All KNHANES interviews and examinations were performed by trained staff according to standardized procedures.

Self-reported questionnaires were administered to the participants to collect data regarding demographic characteristics, smoking status, alcohol consumption, daily exercise level, sleep duration, and history of chronic disease including hypertension, dyslipidemia, and DM. Subjects reported their smoking status by self-administered questionnaires and were divided into two groups: 1) current smokers or 2) non- or ex-smokers, according to their self-reported smoking behavior. A current cigarette smoker was defined as an adult who had smoked at least 100 cigarettes in their lifetime and currently smoked cigarettes. We converted the amount of alcohol consumed per drinking day and the frequency of days drinking in the past month into the mean daily alcohol consumption ( $g$ pure alcohol/day). Using the WHO classification, ${ }^{10}$ heavy drinkers were defined as $>20$ g pure alcohol/day for women and $>40 \mathrm{~g}$ pure alcohol/day for men. Physical activity was defined based on the subjects' responses to a modified version of the International Physical Activity Questionnaire. ${ }^{11}$ Subjects were classified as regular exercisers if they performed $\geq 30$ minutes of moderate-intensity physical activity at least 5 days/week, $\geq 20$ minutes of vigorousintensity physical activity at least 3 days/week, or $\geq 30$ minutes of walking at least 5 days/week, during the previous week.

All anthropometric measurements were obtained by a trained examiner. Waist circumference (WC) was measured at the end of a normal expiration with the arms relaxed at the sides. WC was measured at the mid-point between the margin of the lowest palpable rib and the top of the iliac crest. Body weight and height were measured to the nearest $0.1 \mathrm{~kg}$ and $0.1 \mathrm{~cm}$, respectively, with participants wearing light indoor clothing without shoes. BMI was calculated as the ratio of weight $(\mathrm{kg})$ to height squared $\left(\mathrm{m}^{2}\right)$. Blood pressure measurements were obtained from the right arm using a standard mercury sphygmomanometer (Baumanometer, Copiague, NY, USA). SBP and DBP were measured three times at 5, 10, and 15 minutes and an average was calculated from the second and third measurements. Ophthalmological examinations were performed by a trained ophthalmologist or ophthalmology resident. IOP was measured three times in both eyes using a slit-lamp mounted Goldmann application tonometer (Haag-Streit model BQ-900; Haag-Streit AG, Koeniz, Switzerland). The results were averaged for analysis.

Venous blood samples were obtained after an 8-hour minimum overnight fast. Fasting plasma glucose, triglyceride, and HDL cholesterol levels were measured using an ADVIA1650 autoanalyzer (Siemens Medical Solutions Diagnostics, Erlangen, Germany). Insulin concentrations were measured with an immunoradiometric assay (INS-IRMA; BioSource, Nivelles, Belgium) using the 1470 WIZARD automatic gamma counter (PerkinElmer, Turku, Finland) for the measurement of serum insulin levels. The assay coefficient of variation was $<5 \%$ for insulin. We used the Homeostasis Model Assessment of Insulin Resistance (HOMA-IR) to calculate insulin resistance (IR) ([fasting plasma insulin $(\mu \mathrm{IU} / \mathrm{mL}) \times$ glucose $(\mathrm{mg} / \mathrm{dL})] / 22.5)$. The quantitative insulin-sensitivity check index (QUICKI) value was calculated using the following formula: $(1 /[\log$ fasting plasma insulin $(\mu \mathrm{IU} / \mathrm{mL})+\log$ fasting plasma glucose $(\mathrm{mg} / \mathrm{dL})]$ ). Individuals with $\geq 2.34$ HOMA-IR were defined as 
insulin resistant, and those with $\geq 0.34$ QUICKI were defined as insulin sensitive (IS). ${ }^{12}$

We used the Korean-specific cutoffs of the revised National Cholesterol Education Program-Adult Treatment Panel III to assess for abdominal obesity. ${ }^{13} \mathrm{MetS}$ was defined as any three of the following five metabolic components: 1) $\mathrm{WC} \geq 90 \mathrm{~cm}$ in men and $\geq 85 \mathrm{~cm}$ in women, 2) serum HDL-cholesterol level $<40 \mathrm{mg} / \mathrm{dL}$ in men and $<50 \mathrm{mg} / \mathrm{dL}$ in women, 3) serum triglyceride level $\geq 150 \mathrm{mg} / \mathrm{dL}$ or treatment of dyslipidemia, 4) blood pressure $\geq 130 / 85 \mathrm{mmHg}$ or treatment of hypertension, and 5) fasting glucose level $\geq 100$ $\mathrm{mg} / \mathrm{dL}$ or treatment of type 2 diabetes.

\section{Statistical analyses}

In KNHANES, the sampling results were weighted to allow for nationally representative prevalence estimates of the Korean population. The weights were calculated by accounting for the complex survey design, survey non-response, and post-stratification. The statistical analysis accounted for the complex sampling design of the KNHANES to minimize selection errors. The estimates reported in this study were obtained with consideration for the primary sampling unit, stratification variables, and sampling weights. The analysis was adjusted for survey year to minimize the variations between survey years. ${ }^{14,15}$ Descriptive data were expressed as the mean value (standard error) or number (\%). Analysis of continuous variables was performed using the chi-squared test, and categorical variables were analyzed using the $t$-test of general linear model; and presented as percentages and standard errors. The clinical characteristics of subjects were compared according to gender and clinical diagnosis of MetS. The mean IOPs were compared between different MetS components, according to gender, among participants with MetS. We grouped the patients into different categories of MetS components and compared the mean IOPs between the groups with elevated parameters and those without. For example, to determine the correlation between obesity and IOP, differences in IOP between the obese and non-obese groups were analyzed. Obesity was defined as BMI 25 or higher. Simple and multiple logistic regression analyses were applied to evaluate the association between MetS and ocular hypertension (IOP $>21 \mathrm{mmHg}$ ). Calculations were performed after adjusting for age, BMI, smoking, heavy drinking, and regular exercise. All analyses were performed using SPSS (Version 18.0; SPSS Inc., Chicago, IL, USA) and $P$-values $<0.05$ were considered statistically significant. All statistical tests were two-tailed.

\section{Results}

The clinical characteristics of the study populations are summarized in Table 1. There were 1,915 men and 2,282 women

Table I Clinical characteristics of study populations according to the clinical diagnosis of MetS

\begin{tabular}{|c|c|c|c|c|c|c|}
\hline & \multicolumn{3}{|l|}{ Men } & \multicolumn{3}{|l|}{ Women } \\
\hline & \multirow{2}{*}{$\begin{array}{l}\text { without MetS } \\
(n=5,453)\end{array}$} & \multirow{2}{*}{$\begin{array}{l}\text { With MetS } \\
(n=I, 9 \mid 5)\end{array}$} & \multirow[t]{2}{*}{$P$-value } & \multirow{2}{*}{$\begin{array}{l}\text { Without MetS } \\
(n=7,510)\end{array}$} & \multirow{2}{*}{$\begin{array}{l}\text { With MetS } \\
(n=2,282) \\
\end{array}$} & \multirow[t]{2}{*}{$P$-value } \\
\hline & & & & & & \\
\hline Age (years) & $37.27 \pm 0.21$ & $54.86 \pm 0.29$ & $<0.001$ & $42.57 \pm 0.28$ & $59.34 \pm 0.42$ & $<0.001$ \\
\hline BMI $\left(\mathrm{kg} / \mathrm{m}^{2}\right)$ & $22.13 \pm 0.4$ & $26.27 \pm 0.07$ & $<0.001$ & $22.4 \pm 0.15$ & $26.23 \pm 0.11$ & $<0.001$ \\
\hline WC $(\mathrm{cm})$ & $75.28 \pm 0.13$ & $89.69 \pm 0.18$ & $<0.001$ & $75.26 \pm 0.17$ & $87.91 \pm 0.28$ & $<0.001$ \\
\hline SBP $(\mathrm{mmHg})$ & $111 \pm 0.18$ & $|28.5| \pm 0.3 \mid$ & $<0.001$ & $109.89 \pm 0.27$ & $130.64 \pm 0.46$ & $<0.001$ \\
\hline $\mathrm{DBP}(\mathrm{mmHg})$ & $71.98 \pm 0.14$ & $80.98 \pm 0.20$ & $<0.001$ & $70.79 \pm 0.18$ & $79.22 \pm 0.27$ & $<0.001$ \\
\hline FBS (mg/dL) & $91.95 \pm 0.17$ & $111.89 \pm 0.52$ & $<0.001$ & $90.80 \pm 0.20$ & $\mathrm{III} . \mathrm{II} \pm 0.83$ & $<0.001$ \\
\hline $\mathrm{HDL}(\mathrm{mg} / \mathrm{dL})$ & $55.06 \pm 0.14$ & $44.37 \pm 0.20$ & $<0.001$ & $57.93 \pm 0.19$ & $46.14 \pm 0.28$ & $<0.001$ \\
\hline TG (mg/dL) & $105.44 \pm 0.85$ & $220.04 \pm 3.25$ & $<0.001$ & $91.28 \pm 0.78$ & $187.08 \pm 3.01$ & $<0.001$ \\
\hline Mean IOP $(\mathrm{mmHg})$ & $13.86 \pm 0.05$ & $14.43 \pm 0.07$ & $<0.001$ & $13.68 \pm 0.06$ & $14.29 \pm 0.08$ & $<0.001$ \\
\hline Left IOP $(\mathrm{mmHg})$ & $13.86 \pm 0.05$ & $14.44 \pm 0.07$ & $<0.001$ & $13.67 \pm 0.06$ & $14.32 \pm 0.09$ & $<0.001$ \\
\hline Right IOP $(\mathrm{mmHg})$ & $13.86 \pm 0.05$ & $|4.4| \pm 0.07$ & $<0.001$ & $13.69 \pm 0.06$ & $14.27 \pm 0.09$ & $<0.001$ \\
\hline Ocular hypertension & $28(0.5)$ & $21(1.3)$ & 0.012 & I4 (0.2) & $18(0.7)$ & 0.016 \\
\hline HOMA-IR $\geq 2.34$ & $1,504(30.4)$ & $\mathrm{I}, 276(67.9)$ & $<0.001$ & I,869 (27.8) & $1,539(70.4)$ & $<0.001$ \\
\hline $\mathrm{QUICKI} \leq 0.33$ & I,059 (2I.2) & $\mathrm{I}, 073(56.5)$ & $<0.001$ & $\mathrm{I}, 232(\mathrm{I} 8.2)$ & $1,293(59.9)$ & $<0.001$ \\
\hline Heavy drinkers (\%) & $3,729(74.0)$ & $\mathrm{I}, 293(74.2)$ & 0.001 & $2,373(36.0)$ & $418(22.1)$ & $<0.001$ \\
\hline Current smoking (\%) & $2,350(52.7)$ & $739(53.5)$ & $<0.001$ & $442(6.9)$ & $107(5.7)$ & 0.049 \\
\hline Regular exercise & $3,140(58.2)$ & $\mathrm{I}, 044(53.8)$ & 0.007 & $3,860(52.2)$ & $\mathrm{I}, \mathrm{I} 46(50.0)$ & 0.18 \\
\hline Adequate sleep duration & $3,173(58.9)$ & $\mathrm{I}, \mathrm{I} 37(57.8)$ & 0.438 & $4,587(52.4)$ & $1,212(53.2)$ & $<0.001$ \\
\hline
\end{tabular}

Notes: Data are presented as mean \pm standard error or unweighted number (\%). The definition of ocular hypertension was a mean IOP $>2 \mathrm{I}$ mmHg.

Abbreviations: BMI, body mass index; FBS, fasting blood sugar; HDL, high-density lipoprotein cholesterol; HOMA-IR, Homeostasis Model Assessment of Insulin Resistance; IOP, intraocular pressure; MetS, metabolic syndrome; QUICKI, quantitative insulin-sensitivity check index; TG, triglycerides; WC, waist circumference. 
with MetS included in the study. The mean age was higher in men and women with MetS than healthy subjects: 54.86 vs 37.27 years in men and 59.34 vs 42.57 years in women. The subjects with MetS had significantly higher IOP levels than those without MetS. The mean IOP was $13.86( \pm 0.05) \mathrm{mmHg}$ in men without MetS, and $14.33( \pm 0.07) \mathrm{mmHg}$ in men with MetS. Similarly, in females, the mean IOP was $13.68( \pm 0.06)$ $\mathrm{mmHg}$ in women without MetS and $14.29( \pm 0.08) \mathrm{mmHg}$ in women with MetS. The prevalence of ocular hypertension was higher in the MetS group in both men and women: $1.3 \%$ vs $0.5 \%$ in men, and $0.7 \%$ vs $0.2 \%$ in women. The subjects with MetS had a significantly higher BMI, WC, SBP, triglycerides (TG) level, and fasting blood sugar levels than those without MetS in both sexes. The average sleep duration was significantly longer in subjects without MetS than in subjects with MetS in both men and women. There was no consistent statistically significant difference in smoking, regular exercise, or occupation in either sex. A comparison of the mean values of IOP according to different metabolic components in the MetS subjects showed that both men and women with high blood pressure and elevated fasting glucose levels had significantly higher IOP levels when compared to subjects without these metabolic components $(P<0.05$, respectively) (Table 2). No correlation was found between abdominal obesity and an elevation of IOP.

Table 3 shows a comparison of the mean values of IOP according to subgroups. IOP was significantly higher in the obese group, regardless of the presence or absence of MetS in men.
The subjects with high blood pressure had significantly higher IOP levels than those without hypertension in both men and women. Men with IR and obesity had significantly higher IOP levels regardless of the diagnosis of MetS. However, women with IR and obesity had significantly higher IOP levels without MetS. Table 4 shows the results of the logistic regression analyses assessing the relationship of MetS with ocular hypertension.

The univariate logistic regression analysis between ocular hypertension and MetS indicated that age, BMI, high blood pressure, elevated fasting glucose levels, and elevated TG levels showed a significantly positive association with ocular hypertension in men. However, elevated blood glucose was the only variable significantly associated with ocular hypertension in women $(P<0.05)$. In the final multiple logistic regression model (Table 5), the odds ratios (ORs) for ocular hypertension were 2.111 (95\% CI, 1.090-4.088) and 2.784 (95\% CI 1.221-6.347), respectively, in men and women, after adjustment for age (model 1). After adjusting for age and BMI (model 2), the ORs in men and women were 1.697 (95\% CI 0.803-3.586) and 1.066 (95\% CI 0.839-1.354), respectively. After adjusting for age, BMI, smoking, heavy drinking, regular exercise, and adequate sleep duration (model 3), the ORs for ocular hypertension in men were 1.685 (95\% CI $0.718-3.956)$ and $2.829(95 \%$ CI $0.933-8.579)$ in women.

\section{Discussion}

In this cross-sectional study, after adjusting for age, we found a positive association between IOP and MetS in Korean

Table 2 Comparison of the mean values of intraocular pressure according to metabolic components in MetS subjects

\begin{tabular}{|c|c|c|c|c|c|c|}
\hline & \multicolumn{3}{|l|}{ Men } & \multicolumn{3}{|c|}{ Women } \\
\hline & $\mathbf{n}$ & Mean \pm SE & $P$-value & $\mathbf{n}$ & Mean \pm SE & $P$-value \\
\hline \multicolumn{7}{|c|}{ Abdominal obesity } \\
\hline No & 685 & $14.19 \pm 0.08$ & \multirow[t]{2}{*}{0.125} & 707 & $14.12 \pm 0.08$ & \multirow[t]{2}{*}{0.596} \\
\hline Yes & 1,228 & $14.34 \pm 0.1$ & & 1,563 & $14.07 \pm 0.07$ & \\
\hline \multicolumn{7}{|c|}{ High blood pressure } \\
\hline No & 401 & $14.09 \pm 0.08$ & \multirow[t]{2}{*}{$<0.001$} & 473 & $13.9 \pm 0.07$ & \multirow[t]{2}{*}{0.001} \\
\hline Yes & 1,512 & $14.43 \pm 0.09$ & & $\mathrm{I}, 808$ & $14.19 \pm 0.08$ & \\
\hline \multicolumn{7}{|c|}{ Elevated fasting glucose } \\
\hline No & 506 & $14.06 \pm 0.08$ & \multirow[t]{2}{*}{$<0.001$} & 806 & $13.83 \pm 0.07$ & \multirow[t]{2}{*}{$<0.001$} \\
\hline Yes & $\mathrm{I}, 403$ & $14.43 \pm 0.1$ & & $\mathrm{I}, 456$ & $14.26 \pm 0.08$ & \\
\hline \multicolumn{7}{|c|}{ Low HDL cholesterol } \\
\hline No & 980 & $14.43 \pm 0.07$ & \multirow[t]{2}{*}{0.001} & 604 & $14.15 \pm 0.07$ & \multirow[t]{2}{*}{0.96} \\
\hline Yes & 916 & $14.1 \pm 0.11$ & & $\mathrm{I}, 642$ & $14.04 \pm 0.08$ & \\
\hline \multicolumn{7}{|c|}{ Elevated triglycerides } \\
\hline No & 317 & $14.06 \pm 0.09$ & \multirow[t]{2}{*}{$<0.001$} & 581 & $13.97 \pm 0.07$ & \multirow[t]{2}{*}{0.062} \\
\hline Yes & 1,588 & $14.45 \pm 0.09$ & & $\mathrm{I}, 685$ & $14.12 \pm 0.08$ & \\
\hline
\end{tabular}

Note: The MetS components were defined as: abdominal obesity (waist circumference of men $\geq 90 \mathrm{~cm}$, women $\geq 85 \mathrm{~cm}$ ); high blood pressure (systolic $\geq 130 \mathrm{mmHg}$, diastolic $\geq 85 \mathrm{mmHg}$ ); elevated fasting glucose ( $\geq 100 \mathrm{mg} / \mathrm{dL}$ ); low HDL cholesterol (HDL cholesterol of men $<40 \mathrm{mg} / \mathrm{dL}$, women $<50 \mathrm{mg} / \mathrm{dL}$ ); and elevated triglycerides ( $\geq \mathrm{I} 50 \mathrm{mg} / \mathrm{dL}$ ). Abbreviations: HDL, high-density lipoprotein; MetS, metabolic syndrome. 
Table 3 Comparison of mean values of IOP according to subgroups

\begin{tabular}{|c|c|c|c|c|c|c|c|c|}
\hline & \multicolumn{4}{|l|}{ Men } & \multicolumn{4}{|l|}{ Women } \\
\hline & IOP without MetS & $P$-value & IOP with MetS & $P$-value & IOP without MetS & $P$-value & IOP with MetS & $P$-value \\
\hline \multicolumn{9}{|c|}{$\mathrm{SBP}(\mathrm{mmHg})$} \\
\hline$\leq 139$ & $14.04 \pm 0.07$ & \multirow[t]{2}{*}{0.613} & $14.48 \pm 0.11$ & \multirow[t]{2}{*}{0.139} & $13.66 \pm 0.06$ & \multirow[t]{2}{*}{0.01} & $14.19 \pm 0.1$ & \multirow[t]{2}{*}{0.04} \\
\hline$\geq 140$ & $14.14 \pm 0.20$ & & $14.80 \pm 0.20$ & & $14.04 \pm 0.15$ & & $14.5 \pm 0.13$ & \\
\hline \multicolumn{9}{|c|}{ DBP $(\mathrm{mmHg})$} \\
\hline$\leq 89$ & $14.02 \pm 0.07$ & \multirow[t]{2}{*}{0.01} & $|4.5| \pm 0.1 \mid$ & \multirow[t]{2}{*}{0.352} & $13.67 \pm \mid 3.97$ & \multirow[t]{2}{*}{0.128} & $14.23 \pm 0.09$ & \multirow[t]{2}{*}{0.023} \\
\hline$\geq 90$ & $14.46 \pm 0.18$ & & $14.68 \pm 0.18$ & & $13.98 \pm 0.2$ & & $14.65 \pm 0.18$ & \\
\hline \multicolumn{9}{|c|}{ HOMA-IR } \\
\hline$\leq 2.33$ & $13.94 \pm 0.07$ & \multirow[t]{2}{*}{0.002} & $14.29 \pm 0.1$ & \multirow[t]{2}{*}{0.013} & $13.61 \pm 0.07$ & \multirow[t]{2}{*}{0.001} & $14.28 \pm 0.13$ & \multirow[t]{2}{*}{0.875} \\
\hline$\geq 2.34$ & $14.29 \pm 0.11$ & & $14.69 \pm 0.1$ & & $13.89 \pm 0.09$ & & $14.3 \mid \pm 0.1$ & \\
\hline \multicolumn{9}{|l|}{ QUICKI } \\
\hline$\geq 0.34$ & $13.89 \pm 0.07$ & \multirow[t]{2}{*}{$<0.001$} & $14.21 \pm 0.17$ & \multirow[t]{2}{*}{0.007} & $13.61 \pm 0.07$ & \multirow[t]{2}{*}{$<0.001$} & $14.33 \pm 0.15$ & \multirow[t]{2}{*}{0.943} \\
\hline$\leq 0.33$ & $14.35 \pm 0.13$ & & $14.74 \pm 0.12$ & & $14.02 \pm 0.1$ & & $14.34 \pm 0.1 \mid$ & \\
\hline \multicolumn{9}{|c|}{ BMI $\left(\mathrm{kg} / \mathrm{m}^{2}\right)$} \\
\hline$\leq 24.9$ & $13.98 \pm 0.07$ & \multirow[t]{2}{*}{0.04} & $14.2 \pm 0.15$ & \multirow[t]{2}{*}{0.001} & $13.64 \pm 0.06$ & \multirow[t]{2}{*}{0.027} & $14.33 \pm 0.13$ & \multirow[t]{2}{*}{$0.65 I$} \\
\hline$\geq 25$ & $14.20 \pm 0.10$ & & $14.72 \pm 0.72$ & & $13.85 \pm 0.1$ & & $14.27 \pm 0.1$ & \\
\hline
\end{tabular}

Abbreviations: BMI, body mass index; HOMA-IR, Homeostasis Model Assessment of Insulin Resistance; IOP, intraocular pressure; MetS, metabolic syndrome; QUICKI, quantitative insulin-sensitivity check index.

Table 4 Univariate logistic regression analyses showing the association of MetS to ocular hypertension in all subjects

\begin{tabular}{|c|c|c|c|c|}
\hline \multirow[b]{2}{*}{ Variables } & \multicolumn{2}{|l|}{ Men } & \multicolumn{2}{|c|}{ Women } \\
\hline & ORs & $95 \% \mathrm{Cl}$ & ORs & $95 \% \mathrm{Cl}$ \\
\hline Age (10 years) & 1.183 & $1.041-1.344$ & 1.206 & $0.942-1.543$ \\
\hline BMI $\left(\mathrm{kg} / \mathrm{m}^{2}\right)$ & 1.093 & $1.02 I-1.169$ & 1.068 & $0.993-1.149$ \\
\hline Abdominal obesity & 1.788 & $0.739-4.324$ & 0.972 & $0.394-2.394$ \\
\hline High blood pressure & 2.989 & $1.533-5.828$ & 1.991 & $0.825-4.805$ \\
\hline Elevated fasting glucose & 2.162 & $1.122-4.167$ & 2.611 & $1.068-6.385$ \\
\hline Elevated triglycerides & 2.339 & $1.116-4.905$ & 1.13 & $0.465-2.750$ \\
\hline Low HDL cholesterol & 0.911 & $0.408-2.033$ & 1.998 & $0.824-4.842$ \\
\hline High HOMA-IR & 1.811 & $0.945-1.080$ & 2.326 & $0.829-6.525$ \\
\hline Low QUICKI & 2.133 & $0.933-4.875$ & 1.931 & $0.656-5.679$ \\
\hline MetS & 2.375 & $1.238-4.555$ & 3.089 & $1.293-7.382$ \\
\hline Heavy drinking & 1.729 & $0.618-4.839$ & 0.772 & $0.275-2.169$ \\
\hline Smoking & 1.939 & $0.609-6.174$ & 0.755 & $0.135-4.22 \mid$ \\
\hline Regular exercise & 1.063 & $0.548-2.065$ & 1.418 & $0.542-3.706$ \\
\hline Adequate sleep duration & 1.25 & $0.594-2.630$ & 0.613 & $0.251-1.494$ \\
\hline
\end{tabular}

Note: The components of MetS were defined as: abdominal obesity (waist circumference of men $\geq 90 \mathrm{~cm}$, women $\geq 85 \mathrm{~cm}$ ); high blood pressure (systolic $\geq 130 \mathrm{mmHg}$, diastolic $\geq 85 \mathrm{mmHg}$ ); elevated fasting glucose ( $\geq 10 \mathrm{mg} / \mathrm{dL}$ ); low HDL cholesterol (HDL cholesterol of men $<40 \mathrm{mg} / \mathrm{dL}$, women $<50 \mathrm{mg} / \mathrm{dL}$ ); and elevated triglycerides $(\geq 150$ $\mathrm{mg} / \mathrm{dL})$; high HOMA-IR ( $\geq 2.34)$; low QUICKI ( $\leq 0.33)$.

Abbreviations: BMI, body mass index; HDL, high-density lipoprotein cholesterol; HOMA-IR, Homeostasis Model Assessment of Insulin Resistance; MetS, metabolic syndrome; QUICKI, quantitative insulin-sensitivity check index.

Table 5 Multiple logistic regression analyses showing the association of metabolic syndrome to ocular hypertension

\begin{tabular}{|l|l|l|l|l|}
\hline & \multicolumn{2}{|l|}{ Men } & \multicolumn{2}{l|}{ Women } \\
\cline { 2 - 5 } & ORs & $\mathbf{9 5 \%} \mathbf{C l}$ & ORs & $\mathbf{9 5 \%} \mathbf{C l}$ \\
\hline Model I & $2.11 \mathrm{I}$ & $1.090-4.088$ & 2.784 & $\mathrm{I} .22 \mathrm{I}-6.347$ \\
\hline Model 2 & $\mathrm{I} .697$ & $0.803-3.586$ & 1.066 & $0.839-1.354$ \\
\hline Model 3 & 1.685 & $0.718-3.956$ & 2.829 & $0.933-8.579$ \\
\hline
\end{tabular}

Notes: Model I. Adjusted for age. Model 2. Adjusted for age and BMI. Model 3. Adjusted for age, BMI, smoking, heavy drinking, regular exercise, and adequate sleep duration.

Abbreviation: BMI, body mass index. adults without glaucoma. Previous studies have found that an elevated IOP was associated with elevated blood pressure, ${ }^{16,17}$ elevated blood glucose levels, ${ }^{18}$ and with obesity. ${ }^{4}$ In this study, we found significant differences in IOP according to the degree of IR.

In the current study, we found that subjects with a MetS component are prone to a greater elevation in IOP than those without MetS components. This result is supported by the finding that IOP was significantly correlated with the 
presence of MetS. Among subjects with MetS, high blood pressure and elevated fasting blood glucose levels had significant effects on IOP. Most previous studies have consistently reported a significant influence of blood pressure on IOP. ${ }^{19,20}$ High blood pressure has been considered to elevate IOP by not only increasing ciliary artery pressure and increasing the production of aqueous humor but also through an increase in serum corticosteroids and sympathetic tone. ${ }^{21} \mathrm{High}$ blood pressure was associated with increase in IOP in men. Hypertension is a risk factor for cardiovascular disease and is associated with increased IOP. Assessing the IOP among asymptomatic patients with hypertension as part of primary care may be a simple but effective strategy to ensure earlier detection of glaucoma.

The association between an elevated fasting blood glucose and ocular hypertension was significant in both men and women in this study. However, the mechanism of how hyperglycemia affects IOP is not fully understood. Possible reasons for this association are an increased osmotic gradient induced by an elevated blood glucose, with a consequent fluid shift into the intraocular space, and autonomic dysfunction. ${ }^{22}$ Our analyses used two indices of IR: the HOMA-IR and the QUICKI. The HOMA-IR is a widely used index of IR that can be calculated from fasting insulin and glucose levels. ${ }^{23}$ Many previous studies have reported that an increased fasting glucose level is a risk factor for an elevated IOP; therefore, we used a second IS index, the QUICKI, that is derived from the inverse sum of the logarithms of the fasting insulin and fasting glucose levels. The QUICKI correlates well with glucose clamp studies ( $r=0.78$ ) and is useful for measuring IS, which is the inverse of IR. ${ }^{24}$ Regardless of the index chosen, the IOP was significantly higher in subjects with a severe degree of IR, with the exception of that seen in women with MetS. Also, in women with MetS, there was no association of IOP with BMI.

Our study has several limitations. First, our study used a cross-sectional design, which did not clarify the effect of causal relationships; therefore, additional prospective studies are needed to establish a cause and effect relationship between ocular hypertension and MetS. Second, we could not fully exclude the effects of recall bias since our study included lifestyle factor data based on a self-reported questionnaire survey. Lastly, we did not assess the levels of endogenous cortisol and steroid hormones that could possibly cause morphological changes in the trabecular meshwork and the intraor extraocular tissues, affecting the IOP balance. Also, we did not assess bone mass, which could affect IOP, especially since the concentration of osteocalcin is associated with IR.
On the other hand, a major strength of our study was the use of data from a nationally representative sample of the adult population of Korea. Another strength was the use of a standardized manual for conducting clinical assessments, anthropometric measurements, and biochemical examinations by trained examiners and interviewers.

The prevalence of MetS is rapidly increasing worldwide because of sedentary lifestyles and unhealthy diets. This study showed a significant correlation between IOP and MetS. Future studies should be carried out to investigate the following points: 1) the therapeutic benefits of lifestyle interventions for the prevention and treatment of MetS and the effect on lowering IOP, and 2) prospective studies analyzing the influence of central retinal thickness on future IOP. In summary, we have shown that individuals with MetS are more likely to have an elevated IOP. This study also showed that four of the five components of MetS (elevated fasting plasma glucose, elevated blood pressure, elevated triglyceride, and low HDL) were associated with higher IOPs.

\section{Conclusion}

In this cross-sectional study, ocular hypertension was associated with MetS in Korean adults. These findings also suggest that IOP changes may be associated with MetS, and particularly, IR.

\section{Disclosure}

The authors report no conflicts of interest in this work.

\section{References}

1. Susanna R, de Moraes CG, Cioffi GA, Ritch R. Why do people (still) go blind from glaucoma? Transl Vis Sci Technol. 2015;4(2):1.

2. Lazaro C, Garcia-Feijoo J, Castillo A, Perea J, Martinez-Casa JM, Garcia-Sanchez J. Impact of intraocular pressure after filtration surgery on visual field progression in primary open-angle glaucoma. Eur $J$ Ophthalmol. 2007;17(3):357-362.

3. Grundy SM, Brewer HB Jr, Cleeman JI, et al; National Heart, Lung, and Blood Institute. Definition of metabolic syndrome. Circulation. 2004;109(3):433-438.

4. Karadag R, Arslanyilmaz Z, Aydin B, Hepsen IF. Effects of body mass index on intraocular pressure and ocular pulse amplitude. Int $J$ Ophthalmol. 2012;5(5):605-608.

5. Oh SW, Lee S, Park C, Kim DJ. Elevated intraocular pressure is associated with insulin resistance and metabolic syndrome. Diabetes Metab Res Rev. 2005;21(5):434-440.

6. Chang YC, Lin JW, Wang LC, Chen HM, Hwang JJ, Chuang LM. Association of intraocular pressure with the metabolic syndrome and novel cardiometabolic risk factors. Eye (Lond). 2010;24(6):1037-1043.

7. Park SS, Lee EH, Jargal G, Paek D, Cho SI. The distribution of intraocular pressure and its association with metabolic syndrome in a community. J Prev Med Public Health. 2010;43(2):125-130.

8. Girkin CA, Kannel WB, Friedman DS, Weinreb RN. Glaucoma risk factor assessment and prevention: lessons from coronary heart disease. Am J Ophthalmol. 2004;138(3):11-18. 
9. Ministry of Health and Welfare Korea Centers for Disease Control and Prevention. The Fifth Korea National Health and Nutrition Examination Survey Guide Book (KNHANESV 2010-2012) 2010 Jan [cited Jun 5, 2012] Available from: http://knhanes.cdc.go.kr/.

10. Rehm J, Room R, Monteiro M. Ch 12. Alcohol use. In: Ezzati M, Lopez AD, Rodgers A, Murray CJ, editors. Comparative Quantification of Health Risks: Global and Regional Burden of Disease Attributable to Selected Major Risk Factors. World Health Organization, Geneva; 2004:959-1108.

11. Hagströmer M, Oja P, Sjöström M. The International Physical Activity Questionnaire (IPAQ): a study of concurrent and construct validity. Public Health Nutr. 2006;9(6):755-762.

12. Kwon HC, Woo SI, Kim YK. Cut off values of surrogate measures of insulin resistance for metabolic syndrome in Korean non-diabetic adults. Korean J Obes. 2005;14(2):69-75. Korean.

13. Lee SY, Park HS, Kim DJ. et al. Appropriate waist circumference cutoff points for central obesity in Korean adults. Diabetes Res Clin Pract. 2007;75(1):72-80.

14. Kweon S, Kim Y, Jang MJ, et al. Data resource profile: the Korea National Health and Nutrition Examination Survey (KNHANES). Int J Epidemiol. 2014;43(1):69-77.

15. Wang H, Jeong H, Kim NH, et al. Association between beverage intake and obesity in children: the Korea National Health and Nutrition Examination Survey (KNHANES) 2013-2015. Nutr Res Pract. 2018;12(4):307-314.

16. Wang YX, Xu L, Zhang XH, You QS, Zhao L, Jonas JB. Five-year change in intraocular pressure associated with changes in arterial blood pressure and body mass index. The Beijing eye study. PLoS One. 2013;8(10):e77180.
17. Jürgens C, Grossjohann R, Tost FH. Relationship of systemic blood pressure with ocular perfusion pressure and intraocular pressure of glaucoma patients in telemedical home monitoring. Med Sci Monit. 2012;18(11):MT85-MT89.

18. Wu CJ, Fang WH, Kao TW, et al. Postprandial glucose as a risk factor for elevated intraocular pressure. PLoS One. 2016;11(12):e0168142.

19. Guidoboni G, Harris A, Cassani S, et al. Intraocular pressure, blood pressure, and retinal blood flow autoregulation: a mathematical model to clarify their relationship and clinical relevance. Invest Ophthalmol Vis Sci. 2014;55(7):4105-4118.

20. Klein BE, Klein R, Knudtson MD. Intraocular pressure and systemic blood pressure: longitudinal perspective: the Beaver Dam Eye Study. Br J Ophthalmol. 2005;89(3):284-287.

21. Hennis A, Wu SY, Nemesure B, Leske MC; Barbados Eye Studies Group. Hypertension, diabetes, and longitudinal changes in intraocular pressure. Ophthalmology. 2003;110(5):908-914.

22. Pimentel LGM, Gracitelli CPB, da Silva Leticia Sant'ana Cardoso, Souza AKS, Prata TS. Association between glucose levels and intraocular pressure: pre- and postprandial analysis in diabetic and nondiabetic patients. J Ophthalmol. 2015;2015(11):1-5.

23. Matthews DR, Hosker JP, Rudenski AS, Naylor BA, Treacher DF, Turner RC. Homeostasis model assessment: insulin resistance and beta-cell function from fasting plasma glucose and insulin concentrations in man. Diabetologia. 1985;28(7):412-419.

24. Katz A, Nambi SS, Mather K, et al. Quantitative insulin sensitivity check index: a simple, accurate method for assessing insulin sensitivity in humans. J Clin Endocrinol Metab. 2000;85(7):2402-2410.
Diabetes, Metabolic Syndrome and Obesity: Targets and Therapy is an international, peer-reviewed open-access journal committed to the rapid publication of the latest laboratory and clinical findings in the fields of diabetes, metabolic syndrome and obesity research. Original research, review, case reports, hypothesis formation, expert opinion and commentaries are all considered for publication. The manuscript management system is completely online and includes a very quick and fair peer-review system, which is all easy to use. Visit http://www.dovepress.com/testimonials.php to read real quotes from published authors. 